\title{
ANALISIS PENGKONDISI SINYAL UNTUK SENSOR THERMISTOR: STUDI KASUS LINIERISASI SECARA SERI
}

\author{
Wahyu Budi Mursanto \\ Jurusan Teknik Konversi Energi - Politeknik Negeri Bandung \\ (email : wahyupoli@yahoo.com)
}

\begin{abstract}
ABSTRAK
Penelitian ini memanfaatkan sensor thermistor yang banyak dijual di pasaran sebagai alat ukur temperatur (thermometer). Thermistor merupakan resistor yang sangat peka terhadap temperatur. Thermistor yang digunakan mempunyai koefisien tahanan yang negatif atau biasa disebut dengan NTC (Negative Temperature Coefficient). Namun, kenyataannya hubungan perubahan tahanan terhadap temperatur ini adalah non-linier, sehingga untuk keperluan pengukuran temperatur yang akurat diperlukan teknik linierisasi. Untuk linierisasi ini diperlukan data spesifikasi thermistor yang digunakan, namun sayangnya thermistor yang banyak dijual di pasaran tersebut tidak dilengkapi dengan data yang cukup. Pada penelitian ini dilakukan percobaan untuk mendapatkan kembali spesifikasi teknis dari thermistor yang digunakan, untuk kemudian dirancang linierisasinya dengan metoda rangkaian seri, serta aplikasi pengkondisian sinyal dalam rangkaian elektronik sehingga bisa diperoleh besaran temperatur yang diinginkan. Pada aplikasi perancangan range temperature $200 \mathrm{C}$ sampai dengan $500 \mathrm{C}$ diperoleh nilai $\beta$ sebesar 3500 oK dan $R$ seri sebesar 479 Ohm, dengan kesalahan maksimum sebesar 1,25\% atau kesalahan sebesar $0,5 \circ C$.
\end{abstract}

Kata kunci :Thermistor, NTC, linierisasi seri, pengkondisi sinyal.

\section{PENDAHULUAN}

Thermistor merupakan salah satu sensor temperatur yang sering diaplikasikan di dunia industri atau penggunaan seharihari. Sensor temperatur selain thermistor adalah thermokopel, IC sensor, PT-100, dll. Sensor thermistor bisa mempunyai ukuran yang sangat kecil, ringan, dengan berbagai bentuk yang beraneka ragam, namun mudah pecah (fragile). Jangkauan temperaturnya terbatas, jika dibandingkan dengan sensor temperatur lainnya seperti thermokopel atau PT-100. Karena bentuknya yang bisa kecil dengan sensitivitas yang tinggi, maka sensor ini bisa digunakan untuk mengukur perubahan temperatur yang lambat yang tidak dapat dilakukan oleh sensor temperatur lainnya. Dengan bentuk yang kecil, maka konstanta waktu (time constant) dari sensor ini menjadi lebih kecil. Dengan demikian, waktu pengukuran akan menjadi lebih cepat pula.
Pada umumnya thermistor mempunyai koefisien tahanan yang negatif atau biasa disebut dengan NTC (Negative Temperature Coefficient). Artinya, dengan naiknya temperatur, nilai tahanan yang terjadi akan semakin kecil. Perubahan yang terjadi adalah non linier. Gambar-1 memperlihatkan karakteristik perubahan tahanan terhadap temperatur dari suatu thermistor (NTC) yang non-linier.

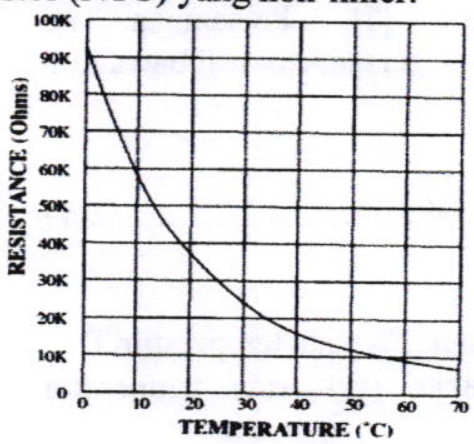

Gambar-1.Karakteristik Thermistor NTC 
Pemakaian sensor thermistor secara langsung dengan karakteristik apa adanya, banyak diaplikasikan untuk kendali on-off suatu peralatan. Pemakaian kendali on-off tentu saja hanya melihat dua keadaan, sehingga efek non-linier bukan merupakan persoalan.

Pada aplikasi untuk pengukuran temperatur yang lebih teliti, karakteristik yang nonlinier merupakan persoalan. Diperlukan teknik linierisasi agar mempermudah dalam pengukuran. Metoda yang sering digunakan untuk linierisasi adalah dengan merangkai secara parallel [1], dengan menggunakan jembatan wheatstone dan secara parallel [2]. Linierisasi secara hardware juga bisa dilakukan dengan menggunakan metoda Op_Amp [3], atau menggunakan metoda rangkaian logaritmik [4].

Dengan semakin majunya teknologi pemrosesan data menggunakan piranti mikroprosesor (computer), maka pembacaan keluaran sensor menjadi lebih mudah, beberapa teknik yang sudah dilakukan diantaranya menggunakan Metoda Persamaan Polinomial Adaptive [5] dan metoda Look-up Table [6].

Pada penelitian ini digunakan linierisasi metoda rangkaian seri. Pemilihan tahanan yang akan diseri dengan thermistor tidaklah sembarangan. Hasil penentuan nilai tahanan tersebut dapat dilakukan dengan menurunkan model matematik thermistor yang digunakan. Salah satu model matematik yang sering digunakan untuk memodelkan thermistor adalah Persamaan Parameter Beta [7]. Persamaan ini diperlihatkan pada persamaan-1 di bawah ini

$R_{T}=R_{0} e^{\beta\left(\frac{1}{T}-\frac{1}{T_{0}}\right)}$

Dengan :

$\mathrm{R}_{\mathrm{T}}=$ Nilai tahanan $(\Omega)$ pada temperatur $\mathrm{T}$

$\mathrm{R}_{0}=$ Nilai tahanan $(\Omega)$ pada temperatur ambien

$\beta=$ Konstanta material thermistor $\left({ }^{\circ} \mathrm{K}\right)$.

$\mathrm{T}_{0}=$ Temperatur ambient $\left({ }^{\circ} \mathrm{K}\right)$
$\mathrm{T}=$ Temperatur $\left({ }^{\circ} \mathrm{K}\right)$

Nilai $R_{0}, T_{0}$ dan $\beta$ biasanya diperoleh dari data spesifikasi pabrikan thermistor. Hampir semua peneliti menggunakan parameter yang ditentukan pabrikan untuk merancang thermometer yang mereka buat $[8,9,10]$. Pada kenyataannya thermistor yang banyak dijumpai di pasar atau toko elektronik tidak dilengkapi dengan data spesifikasi yang tersebut.

Pada penelitian ini digunakan thermistor yang tidak dilengkapi dengan data spesifikasinya. Dengan melakukan serangkaian percobaan akan dicari parameter-parameter yang tidak diketahui tersebut, untuk kemudian dilanjutkan dengan proses linierisasi.

\section{PENENTUAN PARAMETER $\beta$}

Berdasarkan model matematik thermistor Persamaan Parameter Beta, maka ada tiga parameter yang harus ada, yaitu: $R_{0}, T_{0}$, dan $\beta$. $R_{0}$ biasa disebut dengan tahanan thermistor pada temperatur ambien. Biasanya pabrik thermistor menetapkan temperatur ambien pada $25^{\circ} \mathrm{C}$. Dengan demikian, apabila thermistor tersebut dikondisikan pada temperatur $25^{\circ} \mathrm{C}$, maka nilai tahanan yang terukur merupakan nilai dari $\mathrm{R}_{0}$. Pada tahap ini besarnya parameter $\mathrm{R}_{0}$ dan $\mathrm{T}_{0}$ sudah langsung dapat diketahui.

Parameter $\boldsymbol{\beta}$ dapat dicari dengan cara mengukur tahanan thermistor pada temperatur yang lain. Melalui manipulasi matematika sederhana, maka nilai $\beta$ dapat diperoleh dengan mudah. Persamaan-2 memperlihatkan penentuan parameter $\beta$.

$\beta=\frac{\operatorname{Ln}\left(\frac{R_{T}}{R_{0}}\right)}{\left(\frac{1}{T}-\frac{1}{T_{0}}\right)}$

Berdasarkan pada persamaan-2 tersebut, sebenarnya percobaan pengukuran nilai tahanan cukup dilakukan untuk 2 kondisi temperatur saja, namun untuk memperoleh data yang akurat dilakukan 
banyak pengukuran untuk mendapatkan nilai parameter $\beta$ yang lebih representatif.

Untuk melakukan pengukuran tahanan thermistor $\left(\mathrm{R}_{\mathrm{T}}\right)$ pada temperatur $\mathrm{T}$ $\left({ }^{\circ} \mathrm{K}\right)$, kelihatannya mudah, namun sebenarnya tidaklah sesederhana yang dipikirkan/dibayangkan. Beberapa persoalan tersebut yang harus diperhatikan pada saat melakukan percobaan adalah :

1. Thermometer pembanding harus akurat dan presisi.

2. Pengukuran tahanan menggunakan $\mathrm{Ohm}$ meter haruslah memperhatikan faktor self-heating dan dissipation factor thermistor.

3. Pengkondisian media agar temperatur konstan, memerlukan teknik pengendalian lingkungan yang tidak mudah pada temperatur-temperatur uji yang diinginkan.

4. Memastikan bahwa temperatur media sudah konstan dan sensor thermistor sudah berada pada keadaan tunak (steady state) untuk diambil datanya.

Tabel-1 memperlihatkan data percobaan pengukuran tahanan thermistor.

Tabel-1 Data Pengukuran Thermistor

\begin{tabular}{|c|c|c|}
\hline $\left.\mathbf{T} \mathbf{}^{\circ} \mathbf{C}\right)$ & $\left.\mathbf{T}^{{ }^{\circ}} \mathbf{K}\right)$ & $\mathbf{R}_{\mathbf{T}}(\mathbf{k O h m})$ \\
\hline 20 & 293 & 1,215 \\
\hline 25 & 298 & 1,003 \\
\hline 30 & 303 & 0,824 \\
\hline 35 & 308 & 0,685 \\
\hline 40 & 313 & 0,568 \\
\hline 45 & 318 & 0,482 \\
\hline 50 & 323 & 0,401 \\
\hline 55 & 328 & 0,343 \\
\hline 60 & 333 & 0,287 \\
\hline 65 & 338 & 0,248 \\
\hline 70 & 343 & 0,210 \\
\hline 75 & 348 & 0,185 \\
\hline 80 & 353 & 0,155 \\
\hline 85 & 358 & 0,134 \\
\hline 90 & 363 & 0,120 \\
\hline 95 & 368 & 0,106 \\
\hline
\end{tabular}

Gambar-2 memperlihatkan grafik hasil percobaan. Tampak bahwa hasil percobaan memperlihatkan kurva yang non-linier,

Berdasarkan pada Tabel 1 tersebut jelas bahwa nilai $\mathrm{T}_{0}=25^{\circ} \mathrm{C}$ dan $\mathrm{R}_{0}=1,003 \mathrm{kOhm}$. Dengan menggunakan data pengukuran untuk $\mathrm{T}=25^{\circ} \mathrm{C}$ dan $\mathrm{T}=20^{\circ} \mathrm{C}$, dan menggunakan persamaan-2, maka diperoleh nilai $\beta$ sebesar 3349 . Dengan menggunakan cara yang sama untuk titik-titik pengukuran yang lain, maka diperoleh nilai $\beta$ sebagaimana ditunjukkan pada tabel-2. Semua perhitungkan didasarkan terhadap data pada temperatur ambien $25^{\circ} \mathrm{C}$.

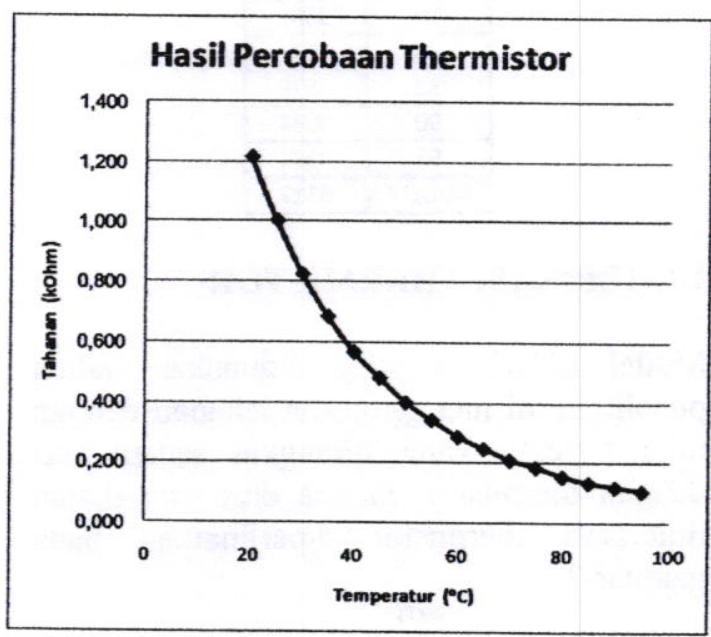

Gambar-2 Kurva non-linier nilai tahanan

Berdasarkan data pada tabel-2 diperoleh nilai rerata $\beta$ sebesar $3517^{\circ} \mathrm{K}$. Berdasarkan pengalaman dan berdasarkan data sheet dari beberapa pabrikan thermistor, nilai $\beta$ sudah tertentu di beberapa nilai sebagaimana ditetapkan oleh pabrikan. Sebagai contoh nilai-nilai $\beta\left({ }^{\circ} \mathrm{K}\right)$ pabrikan adalah 3100,3250 , 3350, 3500, 3650, 3900,dll [11]. Dengan membandingkan nilai $\beta$ tersebut, nilai sebenarnya $\beta$ dari thermistor uji adalah sebesar $3500^{\circ} \mathrm{K}$.

Dengan demikian model matematik untuk thermistor yang digunakan dalam uji coba ditunjukkan pada persamaan-3, dengan satuan nilai $\mathrm{R}_{\mathrm{T}}$ dinyatakan dalam $\mathrm{kOhm}$. 


$$
R_{T}=1 \cdot e^{3500\left(\frac{1}{T}-\frac{1}{298}\right)}
$$

Tabel-2 Penentuan parameter $\beta\left({ }^{\circ} \mathrm{K}\right)$

\begin{tabular}{|c|c|}
\hline$T\left(^{\circ} \mathbf{C}\right)$ & $\boldsymbol{\beta}$ \\
\hline 20 & 3348 \\
\hline 30 & 3550 \\
\hline 35 & 3500 \\
\hline 40 & 3536 \\
\hline 45 & 3472 \\
\hline 50 & 3530 \\
\hline 55 & 3496 \\
\hline 60 & 3548 \\
\hline 65 & 3519 \\
\hline 70 & 3552 \\
\hline 75 & 3506 \\
\hline 80 & 3571 \\
\hline 85 & 3579 \\
\hline 90 & 3534 \\
\hline 95 & 3521 \\
\hline RERATA & 3517 \\
\hline
\end{tabular}

\section{LINIERISASI THERMISTOR}

Model linierisasi yang digunakan dalam penelitian ini menggunakan tahanan dengan nilai tertentu yang dirangkai secara seri dengan thermistor. Skema dasar rangkaian linierisasi thermistor diperlihatkan pada gambar-3.

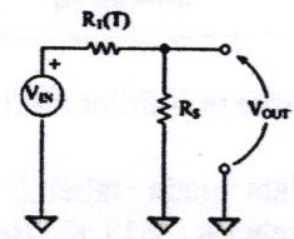

Gambar-3 Rangkaian linierisasi seri
Dengan $\mathrm{R}_{\mathrm{T}}(\mathrm{T})$ adalah tahanan thermistor yang bergantung kepada temperatur $\mathrm{T}$, Rs tahanan seri, $V_{I N}$ sumber tegangan sistem, Vour merupakan tegangan keluaran. Dalam rangkaian listrik konfigurasi pada gambar-3 biasa disebut dengan rangkaian pembagi tegangan (voltage devider). Tegangan keluaran dari rangkaian di gambar-3 dapat dinyatakan dengan persamaan-4 sebagai berikut :

$\frac{V_{\text {OUT }}}{V_{I N}}=\frac{R_{S}}{R_{T}(T)+R_{S}}$

Persoalan pada kasus ini adalah menentukan nilai $R_{S}$ sedemikian rupa sehingga error yang dihasilkan seminimal mungkin pada selang jelajah temperatur (daerah kerja yang diinginkan).

Sebagai contoh ilustrasi dipilih daerah kerja antara $20^{\circ} \mathrm{C}$ sampai $90^{\circ} \mathrm{C}$. Untuk melihat bagaimana karakteristik tegangan keluaran yang dihasilkan, maka dipilih nilai Rs yang maksimum, medium dan minimum sebagai pembanding; yaitu Rs $\max =1,2 \mathrm{kOhm}$, Rs medium sebesar $0,343 \mathrm{kOhm}$ dan Rs min = 0,12 kOhm. Gambar-4 memperlihatkan 3 kurva rasio tegangan berbeda. 


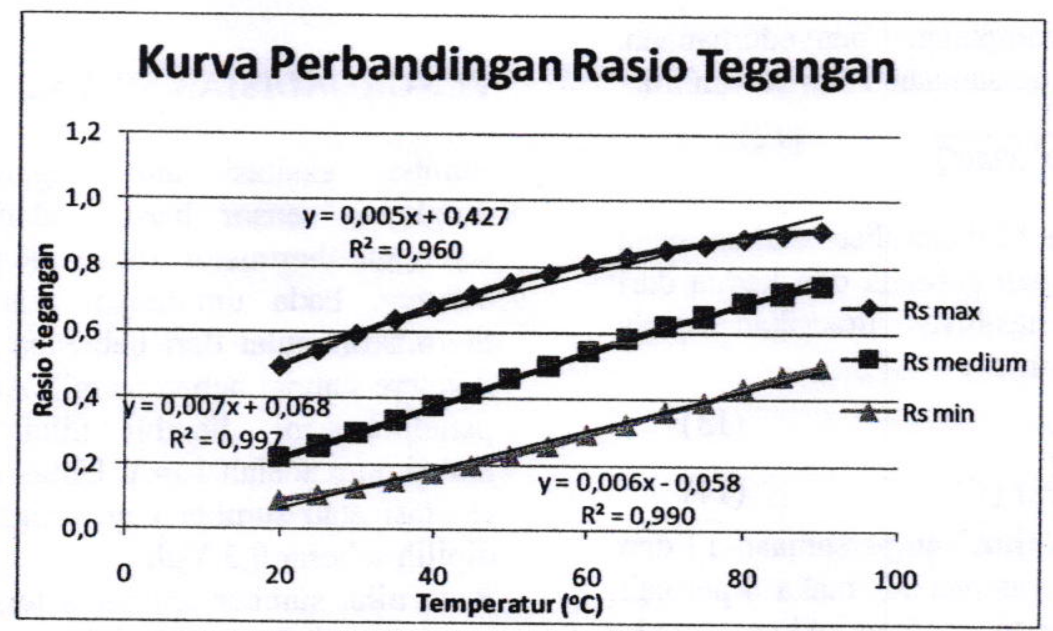

Gambar-4 Kurva perbandingan rasio tegangan

Tampak pada gambar-4 bahwa untuk nilai Rs max, bentuk kurva cenderung cembung (terbuka ke bawah). Pada nilai Rs medium tampak bahwa kurva mempunyai titik belok di sekitar temperatur tengah. Untuk nilai Rs min bentuk kurva adalah cekung (terbuka ke atas). Dengan pendekatan secara linier, maka diperoleh korelasi kelinieran $\left(\mathrm{R}^{2}\right)$ yang berbeda-beda. Hasil korelasi kelinieran yang bagus $\left(R^{2}\right.$ mendekati nilai 1) diperoleh untuk nilai Rs medium,dengan nilai korelasi $\mathrm{R}^{2}$ $=0,997$.

Dari ilustrasi tersebut tampak bahwa nilai Rs yang mendekati nilai tengah merupakan nilai yang mempunyai rasio tegangan dengan kesalahan yang terkecil. Dengan mencari titik belok dari kurva rasio tegangan berarti akan diperoleh nilai Rs yang akan memperkecil kesalahan pengukuran. Secara matematis hal tersebut dapat dilakukan dengan membuat :

$\frac{d^{2}}{d T^{2}}\left(\frac{V_{\text {OUT }}}{V_{I N}}\right)=0$

Dengan membuat suatu fungsi :

$H=\frac{V_{\text {OUT }}}{V_{I N}}=\frac{R_{S}}{R_{T}(T)+R_{S}}$,

maka diperoleh persamaan-6 sebagai berikut

$H=\frac{1}{\frac{R_{T}(T)}{R_{S}}+1}$
Jika persamaan-1 disubstitusikan ke persamaan-6 diperoleh persamaan-7 sebagai berikut :

$$
H=\frac{1}{1+\left[\frac{R_{0}}{R_{S}} e^{\beta\left(\frac{1}{T}-\frac{1}{T_{0}}\right)}\right]}
$$

Jika : $c=\frac{R_{0}}{R_{s}}$

dan

$$
g(T)=e^{\beta\left(\frac{1}{T}-\frac{1}{T_{0}}\right)}
$$

maka, persamaan-7 dapat disederhanakan menjadi persamaan-10 sebagai berikut :

$$
\begin{aligned}
& H=\frac{1}{1+c g(T)} \\
& \frac{d H}{d T}=-\frac{c g^{\prime}(T)}{(1+c g(T))^{2}}
\end{aligned}
$$

$\frac{d^{2} H}{d T^{2}}$

$=-\left[\frac{c g^{\prime \prime}(T)(1+c g(T))^{2}-c g^{\prime}(T)(1+c g(T))}{(1+c g(T))^{4}}\right]$

(11)

Dari persamaan-5, maka :

$$
\frac{d^{2}}{d T^{2}}\left(\frac{V_{O U T}}{V_{I N}}\right)=\frac{d^{2} H}{d T^{2}}=0
$$

Artinya nilai pembilang pada persamaan-11 menjadi sama dengan nol. Dengan 
melakukan serangkaian penyederhanaan, maka diperoleh persamaan-12 di bawah ini.

$c=\frac{g^{\prime \prime}(T)}{2\left[f g^{\prime}(T)\right]^{2}-g^{\prime \prime}(T) g(T)}$

Agar persamaan-12 dapat diselesaikan maka dicari nilai turunan pertama dan kedua dari persamaan-9, hasilnya diberikan pada persamaan-13 dan 14.

$g^{\prime}=-\frac{\beta}{T^{2}} f(T)$

$g^{\prime \prime}=\left[2 \frac{\beta}{T^{3}}+\frac{\beta^{2}}{T^{4}}\right] f(T)$

Dengan mensubstitusikan persamaan-13 dan 14 ke dalam persamaan-12, maka diperoleh hasil sebagaimana ditunjukkan pada persamaan-15.

$c=\frac{\beta+2 T}{(\beta-2 T) g(T)}$ atau :

$c=\frac{\beta+2 T}{(\beta-2 T) e^{\beta\left(\frac{1}{T}-\frac{1}{T_{0}}\right)}}$

Dengan menggabungkan persamaan- 8 dan persamaan 15 , maka diperoleh persamaan16 sebagai berikut :

$R_{S}=R_{0} \frac{(\beta-2 T) e^{\beta\left(\frac{1}{T}-\frac{1}{T_{0}}\right)}}{\beta+2 T}$

Nilai Rs dapat dicari berdasarkan nilai temperatur tengah (di titik belok ) yang diinginkan, $\mathrm{T}=\mathrm{T}_{1}$. Dimana $\mathrm{T}_{1}$ adalah temperatur di titik belok yang diinginkan.

Berdasarkan pada hasil penelitian yang sudah diperoleh tersebut di atas, maka akan dirancang suatu aplikasi sensor thermistor untuk pengukuran pada temperatur antara $20^{\circ} \mathrm{C}$ sampai $50^{\circ} \mathrm{C}$, dimana range pengukuran ini merupakan temperatur udara kerja lingkungan normal sampai dengan temperatur udara kerja di sekitar peralatan $/$ mesin.

Nilai T1 untuk kondisi ini diatur pada $(50+20) / 2=35^{\circ} \mathrm{C}$. Dengan memasukkan nilai-nilai parameter thermistor dan nilai $\mathrm{T}_{1}=35^{\circ} \mathrm{C}\left(308^{\circ} \mathrm{K}\right)$ pada persamaan- 16 , maka diperoleh nilai $\mathrm{Rs}=479 \mathrm{Ohm}$. Nilai resistor ini dapat diperoleh dari tiga resistor sebesar 470 dan 6,3 Ohm dan 2,7 Ohm yang dirangkai secara seri dengan toleransi kesalahan $1 \%$ sudah mencukupi kebutuhan.

\section{PENGKONDISIAN SINYAL}

Sumber eksitasi atau tegangan untuk rangkaian sensor harus sedemikian rupa sehingga thermistor tidak mengalami self heating. Pada umumnya arus kerja dari thermistor mulai dari beberapa ratus mikro Ampere sampai beberapa mili Ampere. Pada penelitian ini diambil nilai arus kerja maksimum adalah $1 \mathrm{~mA}$. Untuk itu tegangan eksitasi atau sumber bagi rangkaian sensor dipilih sebesar 0,5 Volt.

Pada nilai sumber tegangan tersebut, maka tegangan keluaran minimum rangkaian sensor (pada $\mathrm{T}=20^{\circ} \mathrm{C}$ ) adalah sebesar 0,141 Volt, dan tegangan keluaran maksimum (pada $\mathrm{T}=50^{\circ} \mathrm{C}$ ) adalah sebesar 0,272 Volt. Untuk mempermudah display secara langsung, maka tegangan akhir dari pengkondisi sinyal dibuat 2 Volt untuk kondisi minimum dan 5 volt untuk kondisi maksimum.

Berdasarkan perumusan permasalahan di atas maka dibuatlah suatu rangkaian pengkondisi sinyal yang mampu merepresentasikan kondisi yang diinginkan tersebut melalui suatu rangkaian yang disebut dengan Rangkaian Zero dan Span. Untuk memformulasikan permasalahan tersebut di atas, maka dapat direpresentasikan dengan kurva alih (transfer curve) sebagaimana ditunjukkan pada gambar-5.

Penyelesaian secara elektronik dari representasi kurva alih dapat diselesaikan dengan menggunakan rangkaian Zero dan Span sebagaimana diperlihatkan pada gambar-6. Rangkaian Zero dan Span tersusun dari rangkaian penguat penjumlah $\left(\mathrm{Op}-\mathrm{ampU}_{1}\right)$ dan rangkaian pembalik (inverting) pada konfigurasi yang disusun oleh Op-Amp U $\mathrm{U}_{2}$ [12]. 


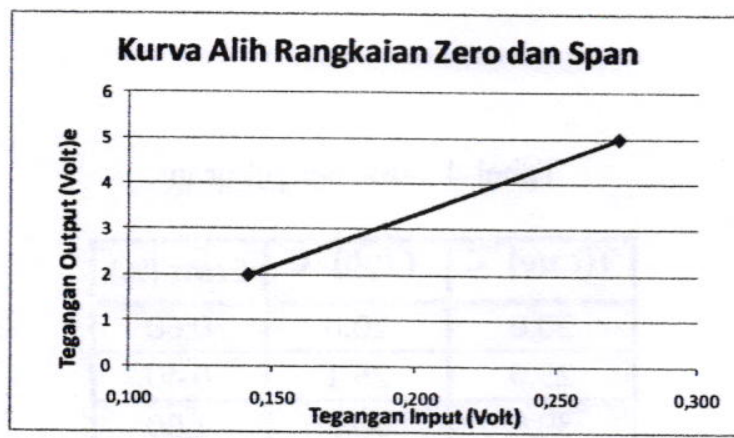

Gambar-5 Kurva Alih

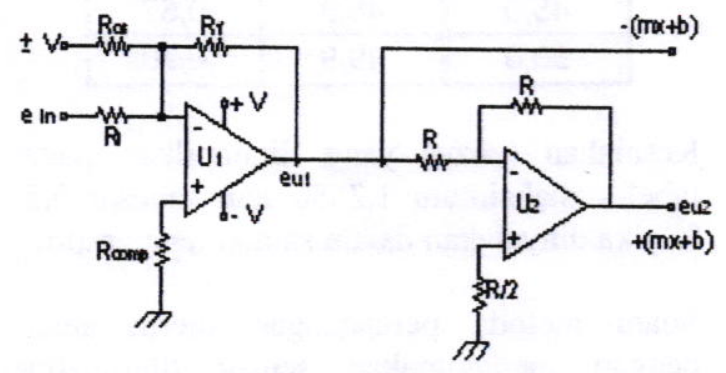

Gambar-6 Rangkaian Zero dan Span

Berdasarkan gambar-6, tegangan keluaran di $\mathrm{e}_{\mathrm{u} 1}$ dapat dinyatakan dengan persamaan-17.

$e_{u 1}=-\left[\left(\frac{R_{f}}{R_{I N}}\right) V_{I N}+\left(\frac{R_{f}}{R_{O S}}\right) V\right]$

Rangkaian penguat operasional $\mathrm{U}_{2}$ merupakan rangkaian pembalik (inverting), sehingga tegangan keluaran $\mathrm{di} \quad \mathrm{e}_{\mathrm{u} 2}$ dinyatakan dengan persamaan-18.

$e_{u 2}=\left[\left(\frac{R_{f}}{R_{I N}}\right) V_{I N}+\left(\frac{R_{f}}{R_{O S}}\right) V\right]$

Berdasarkan pada kurva alih di gambar-5 maka , persamaan garis dari kurva alih tersebut dapat diperoleh melalui perhitungan sederhana dan hasilnya diperlihatkan pada persamaan-19.

$V_{\text {out }}=\left[22,94 V_{I N}-1,242\right]$ Volt

Karena $\mathrm{V}_{\text {out }}=\mathrm{e}_{\mathrm{u} 2}$, maka dari persamaan-18 dan 19 diperoleh hasil sbb :

$\frac{R_{f}}{R_{I N}}=22,94 \quad$ dan $\frac{R_{f}}{R_{O S}} V=-1,242$
Dengan mengambil nilai $R_{f}=100 \mathrm{kOhm}$ dan nilai $\mathrm{V}=-12$ Volt, maka: $\mathrm{R}_{\mathrm{IN}}=4,358$ $\mathrm{kOhm}$, dan $\mathrm{R}_{\mathrm{OS}}=966,56 \mathrm{kOhm}$.

Nilai $\mathbf{R}_{\mathrm{IN}}$ dapat diperoleh dari potensio $5 \mathrm{kOhm}$ yang diserikan dengan resistor tetap sebesar 2,2 kOhm. Potensio 5 $\mathrm{kOhm}$ ini yang disebut dengan potensio Span (aplikasi di industri biasa disebut dengan gain). Dengan mengatur potensio span ini nilai $R_{I N}$ dapat diperoleh. Demikian pula untuk nilai $R_{0 s}$ dapat diperoleh dengan merangkai secara seri resistor potensio 1 MOhm dengan resistor tetap $220 \mathrm{kOhm}$. Potensio sebesar $1 \mathrm{MOhm}$ inilah yang disebut dengan potensio Zero (aplikasi di industri biasa disebut dengan offset). Untuk memperoleh nilai $R_{o s}$ dilakukan dengan cara mengatur potensio Zero ini.

Pada kenyataanya nilai $R_{\mathbb{I N}}$ dan $R_{O S}$ ini hanya sebagai patokan awal, nilai sebenarnya akan bergantung pada hasil kalibrasi potensio Span dan potensio Zero.

Nilai $R$ pada rangkaian Op-Amp di $\mathrm{U}_{2}$ dapat dipilih, misal sebesar $22 \mathrm{kOhm}$. Dengan demikian nilai $\mathrm{R} / 2$ adalah sebesar $11 \mathrm{kOhm}$. Nilai $11 \mathrm{kOhm}$ ini dapat dibuat dengan merangkai secara seri dua resistor sebesar 10 $\mathrm{kOhm}$ dan $1 \mathrm{kOhm}$. Dengan demikian perancangan nilai-nilai resistor dari perangkat keras pengkondisi sinyal sudah dapat diselesaikan.

\section{HASIL DAN PEMBAHASAN}

Berdasarkan pada perancangan yang telah diperoleh, maka bagaimana keluaran dari thermometer ini dapat diketahui melalui suatu simulasi. Hasil simulasi ditunjukkan pada Tabel-3 berikut ini. 
Tabel-3 Tegangan keluaran

\begin{tabular}{|c|c|c|}
\hline $\mathbf{T}\left({ }^{\circ} \mathbf{C}\right)$ & $\mathbf{V}_{\text {RS }}(\mathbf{V})$ & $\mathbf{V}_{\text {out }}(\mathbf{V})$ \\
\hline 20 & 0,141 & 1,99 \\
\hline 25 & 0,162 & 2,47 \\
\hline 30 & 0,184 & 2,97 \\
\hline 35 & 0,206 & 3,48 \\
\hline 40 & 0,228 & 3,99 \\
\hline 45 & 0,250 & 4,49 \\
\hline 50 & 0,271 & 4,99 \\
\hline
\end{tabular}

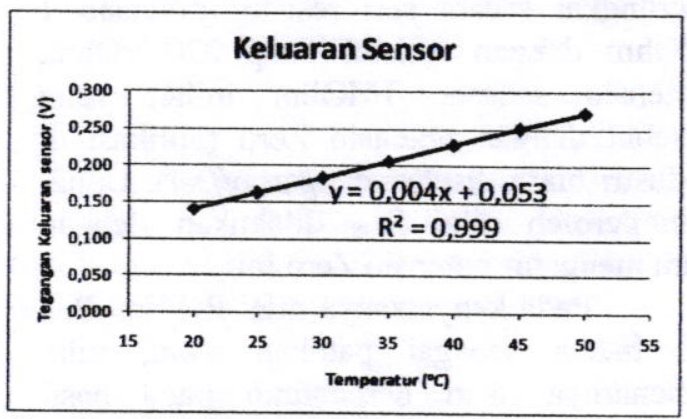

Gambar-7 Keluaran Rangkaian sensor

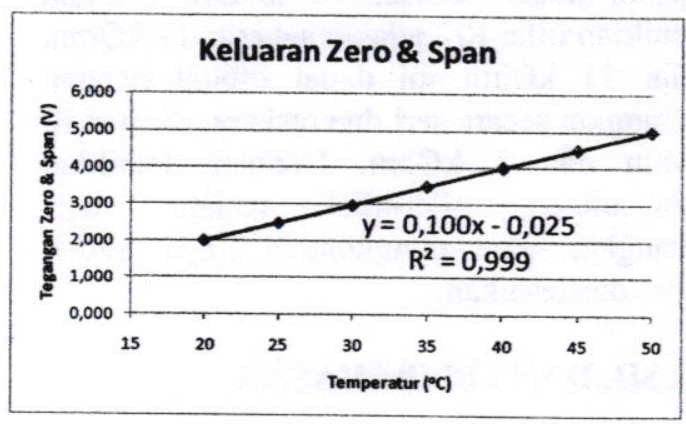

Gambar-8 Keluaran zero dan span

Gambar-7 memperlihatkan kurva tegangan keluaran di tahanan Rs sebagai fungsi dari temperatur, demikian pula pada gambar- 8 memperlihatkan tegangan keluaran dari zero dan span. Berdasarkan gambar-7 dan 8, tampak bahwa korelasi tegangan yang dihasilkan sudah linier $\left(\mathrm{R}^{2}=0,99\right)$.

Tampilan tegangan keluaran zero dan span sudah mewakili temperatur yang diukur dengan cara mengalikan tampilan tegangan dengan faktor 10 .
Tabel-4 Error pengukuran

\begin{tabular}{|c|c|c|}
\hline T(true) $^{\circ} \mathbf{C}$ & $\mathbf{T}^{\text {(uji) }}{ }^{\circ} \mathrm{C}$ & Error (\%) \\
\hline 20,0 & 20,0 & 0,00 \\
\hline 25,0 & 25,1 & 0,40 \\
\hline 30,0 & 30,3 & 1,00 \\
\hline 35,0 & 35,4 & 1,14 \\
\hline 40,0 & 40,5 & 1,25 \\
\hline 45,0 & 45,3 & 0,67 \\
\hline 50,0 & 49,9 & 0,20 \\
\hline
\end{tabular}

Kesalahan (error) yang ditampilkan pada tabel-4 maksimum $1,25 \%$ atau sebesar 0,5 ${ }^{\circ} \mathrm{C}$ jika dinyatakan dalam satuan temperatur.

Suatu metoda perancangan thermometer dengan menggunakan sensor thermistor dengan kasus linierisasi secara seri sudah dilakukan pada penelitian ini. Penelitian ini difokuskan pada sensor thermistor yang tidak dilengkapi dengan data pendukunnya (data sheet) dengan karakteristik NTC.

Pada penelitian ini jangkauan (range) temperatur berkisar dari $20^{\circ} \mathrm{C}$ sampai dengan $50{ }^{\circ} \mathrm{C}$. Kesalahan maksimum yang dihasilkan sebesar $1,25 \%$ atau sebesar 0,5 ${ }^{\circ} \mathrm{C}$

Pemilihan komponen perangkat keras juga akan turut berpengaruh pada hasil yang dicapai. Penggunaan tahanan (resistor) dengan toleransi yang sangat rendah dengan stabilitas temperatur yang konstan akan berpengaruh besar terhadap hasil yang dicapai. Demikian pula pemilihan IC untuk Op-Amp (general purpose) dengan kualitas yang baik diperlukan untuk mendukung pencapaian yang lebih baik. Sebaiknya digunakan IC-IC yang terbuat dari FET, BIFET atau yang setara. Stabilitas catu daya untuk rangkaian sensor juga harus dipastikan untuk menjamin kestabilan tegangan. 


\section{DAFTAR PUSTAKA}

1. Wahyu B.Mursanto, Rony Fachrul, Rancang Bangun Transduser Temperatur Meng-gunakan Sensor Termistor, Jurnal Teknik Energi, Vol. 2 No. 1 April 2012, Politeknik Negeri Bandung.

2. Warsito, Analisis Rangkaian Pengkondis Sinyal Tahap Awal Pada Sensor Pasif: Studi Kasus Untuk Thermistor Tipe NTC, Jurnal Sains Tek. Vol. 11 No.3 Desember 2005, FMIPA Universitas Lampung.

3. R.S. Aloke, Linearization of NTCThermistor Characteristic Using OP-AMP Based In-verting Amplifier, Thesis master of Electrical Engineering, Jadavpur University, 2012.

4. A.A.Khan and R. Sengupta, A linier temperatur/Voltage Con-verter Using Thermistor in Logarithmic Network, IEEE Trans. Instrum. Meas. Vol. IM -33 No.1 pp-2-4 March 1984.

5. Eru Puspita, Teknik Perbaikan Karakteristik suatu Sensor yang Non Linier pada Rang-kaian Elektronik Mengguna-kan Metoda Persamaan Poli-nomial Adaptif, Politeknik Elektronika Negeri Surabaya, 2002.
6. Lars E. Bengtsson, Look-up Table Optimization for Sensor Linearization in Small Embedded Systems., Journal of Sensor Technology, hal. 177-184, tahun 2012.

7. William,W.R., Sensor and Circuits, Mac.Graw Hill Books, London, England, 1992.

8. Slomovitz, D., J. Joskowicz, Error Evaluation of Thermistor Linierizing Circuits, Journal : Measurement of Science Technology Vol.1, 1990.

9. Patranabis, D., Ghosh, S., and Bakshi, C., Linearizing

Transducer Characteristics, IEEE Trans. Instrum. Meas.37, 66-9, 1988.

10. Sengupta, R.N., A Widely Line-ar Temperature to Frequency Converter Using a Thermistor in a Pulse Generator, IEEE Trans. Instrum. Meas.37 62-5, 1988.

11. Murata, Thermistor Data Sheets, 12 january 2012.

12. Jacob, J.M., Industrial Control Electronics Application and Design, Prentice-Hall Inc, Englewood Cliffs, New Jersey, 1989. 